\title{
Personality Preferences in Laboratory Economics Experiments
}

\author{
Kurtis J. Swope \\ U. S. Naval Academy \\ John Cadigan* \\ American University \\ Pamela M. Schmitt \\ U. S. Naval Academy \\ Robert Shupp \\ Ball State University
}

July 2005

\begin{abstract}
Student volunteers at the U.S. Naval Academy (USNA) participated in one of the following oneshot games: a dictator game, an ultimatum game, a trust game, or a prisoner's dilemma game. We find limited support for the importance of personality type for explaining subjects' decisions. With controls for personality preferences, we find little evidence of behavioral differences between males and females. Furthermore, we conclude that seniority breeds feelings of entitlement - seniors at USNA generally exhibited the least cooperative or other-regarding behavior.

Keywords: Experiments; preferences; personality JEL classification: A120; C720; C780

Financial support from the American University Research Award and Ball State University Faculty Research Grant is gratefully acknowledged. The authors would also like to thank participants at the 2004 SABE and 2004 SEA meetings for their comments and helpful suggestions.

*Corresponding author: School of Public Affairs, American University, 4400 Massachusetts Ave., NW, Washington, D.C. 20016 Fax: (202) 885-2347, Phone: (202) 885-6331, Email: jcadigan@american.edu
\end{abstract}




\title{
Personality Preferences in Laboratory Economics Experiments
}

\author{
Abstract \\ Student volunteers at the U.S. Naval Academy (USNA) participated in one of the following one- \\ shot games: a dictator game, an ultimatum game, a trust game, or a prisoner's dilemma game. \\ We find limited support for the importance of personality type for explaining subjects' decisions. \\ With controls for personality preferences, we find little evidence of behavioral differences \\ between males and females. Furthermore, we conclude that seniority breeds feelings of \\ entitlement - seniors at USNA generally exhibited the least cooperative or other-regarding \\ behavior.
}




\section{Introduction}

Subjects in laboratory economics experiments exhibit behavior that frequently deviates significantly from standard game-theoretic predictions based on a limited model of strict selfinterest. Subject decisions in some laboratory experiments may be influenced by psychological variables, such as personality type, in ways that are not captured by standard game-theoretic models. A growing literature in experimental economics examines subjects' decisions from the perspective of personality psychology (see Ben-Ner, et al (2004), Burks, et al (2003), Brandstätter and Güth (2002), Ma, et al (2002), and Boone, et al (1999) for recent examples).

This paper applies the theory of psychological type to gain insight into subject behavior in four laboratory economics experiments: the dictator game, the ultimatum game, the trust game, and the prisoner's dilemma game. The main contribution of the paper is that we show that personality variables have predictive power for behavior in these games that is weakly consistent with expectations based on personality psychology. Outside of our own research, there are no related studies of which we are aware for which collection of personality data is fully separate from collection of experimental data. By using USNA students and the Myers-Briggs Type Indicator (MBTI), our research uniquely avoids potential framing effects of personality test instruments because all students complete the MBTI upon entrance to the Academy. The primary motivation for using the MBTI rather than alternative personality indicators is this prior availability as well as its popularity in the U.S. among industrial psychologists as well the general public.

The MBTI (Myers, et al (1998)) provides information on four psychological preferences of individuals: (1) perception - how a person acquires information, (2) judgment - how a person makes decisions and comes to conclusions, (3) orientation of energy - the degree to which a 
person's attention and energy is directed outward or inward, and (4) attitude towards outer world - the degree to which a person prefers perceiving to judging.

We hypothesize that differences among subjects with regard to judgment and orientation, as measured by the MBTI, can lead to statistically significant, predictable, and observable differences in subjects' decisions. Furthermore, in the presence of appropriate controls for personality preferences, we expect no behavioral differences between males and females. This connects our research to studies on gender differences, including Ben-Ner, et al (2004), Eckel and Grossman (1998, 2001), Solnick (1997), Brown-Kruse and Hummels (1993), and Nowell and Tinkler (1994). Separating the impact of gender from that of personality preferences may help to explain the preponderance of conflicting results in the existing literature.

The paper proceeds as follows. Section 2 describes the experimental design, subjects, setting, and personality test instrument. Section 3 presents experimental results followed by discussion and concluding remarks in Section 4.

\section{Methods}

\subsection{Experimental Design}

We conducted four popular, two-player laboratory experiments: a dictator game, an ultimatum game, a trust game, and a prisoner’s dilemma game. In the two-player dictator game (Kahneman, et al (1986)), player 1 is given a monetary endowment, here $\$ 15$, and the option of giving any amount of her endowment to player 2, who is endowed with $\$ 0 .{ }^{1}$ Player 2 makes no

\footnotetext{
${ }^{1}$ Institutional constraints prevented us from paying a show-up fee in any of our experiments. Some subjects could, and did, leave with $\$ 0$ for their time. While the lack of a show-up fee is generally inconsistent with most experimental studies, it is an interesting extreme experimental environment that may actually be more consistent with standard game-theoretic assumptions which fail to incorporate the presence of a show-up fee.
} 
decision. Based on the assumption that players are concerned only with monetary payoffs, the unique equilibrium prediction has player 1 keep the entire $\$ 15$.

In the simple, two-player ultimatum bargaining game (Güth, et al (1982)), player 1 (the “proposer”) must propose a division of a fixed monetary amount between herself and the second player (the “responder”). Player 2 decides whether to accept or reject the proposal. If player 2 accepts the proposal, each player receives the corresponding monetary amount contained in the proposal. If player 2 rejects the proposal, each player receives a disagreement payoff, here \$0. Because a self-interested player 2 will accept any positive proposal, the game-theoretic prediction has player 1 propose a split that leaves player 2 with the smallest allowable amount, and player 2 accept the proposal.

In the two-player trust game (Berg, et al (1995)), player 1 is endowed with $\$ 10$ and given the option of sending any portion of the $\$ 10$ to player 2. The amount sent is tripled. That is, if player 1 keeps $\$ 5$ and sends $\$ 5$, player 2 receives $\$ 15$. Player 2 is then given the option of returning to player 1 any portion of the tripled amount she received. Because a self-interested player 2 would not return any amount she received, the unique equilibrium prediction has player 1 send $\$ 0$.

In the two-player prisoner's dilemma game, players simultaneously choose one of two strategies, say A or B. If both players choose strategy A, both receive \$5 in our game. If both players choose strategy $B$, both receive $\$ 10$. If players choose opposite strategies, the player choosing option A receives $\$ 20$, while the player choosing option B receives $\$ 2$. Because the payoff to a player from choosing option $\mathrm{A}$ is always higher relative to option B irrespective of the decision of the other player, option A is a dominant strategy. Therefore, both players 
choosing option A is a Nash Equilibrium to this one-shot prisoner's dilemma game under noncooperative play.

\subsection{Subjects and Setting}

Participants were students at USNA in various years of study. Students were invited to participate via email solicitation. Participants reported to and made decisions in different rooms than the individual with whom they were randomly matched. Participants were paid their earnings privately in cash at the conclusion of the experiment. The experimenters verbally assured participants that all players were real. Subjects made decisions in only one experiment. While the solicitation process was quasi-random, we made an attempt to recruit subjects from all personality types.

\subsection{Personality Test Instrument and Behavioral Hypotheses}

Personality tests provide a useful point of departure to control for individual-specific characteristics of subjects in order to test broader game-theoretic hypotheses. They also provide an interesting and meaningful way to examine any direct link between personality measurables and behavior patterns in laboratory economic experiments.

Several alternative personality models are available, though it is beyond the scope and intention of the current research to provide a comprehensive comparison of these to the MBTI or their reliability and validity. References are provided for this purpose. Type A individuals (described as rigid, time-urgent, perfectionist types) versus Type B (relaxed types) can be identified by the Jenkins Activity Survey (JAS) (Jenkins, et al (1979)). The Five-Factor Model (FFM) characterizes individuals according to the five dimensions Neuroticism, Extraversion, Openness to Experience, Agreeableness, and Conscientiousness as measured by the NEO Personality Inventory (NEO-PI) (Costa and McCrae, 1985). 
The MBTI is structured as a four-factor dichotomous approach to identifying personality “types” based on Carl G. Jung’s (1923) theory of psychological type. The MBTI identifies an individual as having a preference for extraversion (E) or introversion (I) in orientation, a preference for sensing $(\mathrm{S})$ or intuition $(\mathrm{N})$ in perception, and a preference for thinking $(\mathrm{T})$ or feeling (F) in judgment. The MBTI also adds a fourth dichotomy not explicitly mentioned by Jung. This fourth dichotomy reflects whether a person prefers to use a judgment (J) attitude or a perception (P) attitude when "interacting with the outside, extraverted world" (Myers, et al, 1998, p. 26).

Briefly, the four type dichotomies are described by the MBTI developers as follows. "In the Extraverted attitude, energy and attention flow out, or are drawn out, to the objects and people in the environment” (Myers, et al, 1998, p. 26). "In the Introverted attitude, energy is drawn from the environment toward inner experience and reflection" (p. 26). Sensing "refers to perceptions observable by way of the senses" (Myers, et al, 1998, p. 24) while intuition "refers to perception of possibilities, meanings, and relationships by way of insight” (p. 24). Thinking judgment leads to a decision "by linking ideas together through logical connections" (p. 24) while feeling judgment leads to a decision "by weighing the relative values and merits of the issues” (p. 24). "In the Judging attitude, a person is concerned with making decisions, seeking closure, planning operations, or organizing activities" (p. 26) while "In the Perceiving attitude, a person is attuned to incoming information” (p. 27). Jung's dichotomous theory of orientation and the four mental processes is illustrated in Figure 1.

\section{(Figure 1 about here)}


The MBTI is a self-report questionnaire designed to identify which orientation and functions are preferred by an individual. For more information on the development and uses of the MBTI, including reliability and validity estimates, consult Myers, et al (1998).

The developers of the MBTI stress that type theory is greater than the sum of the parts. That is, there are important interactions between the dichotomous preferences that may lead to a richer set of behavioral predictions than the four main dichotomies imply. We hypothesize about and test some of the possible interactions below. Figure 2 gives a breakdown of our subject pool by whole MBTI types.

\section{(Figure 2 about here)}

The most common whole type combination in our subject pool is ISTJ. The least common is ISFP. Table 1 provides a summary of our subjects by gender and MBTI dichotomies. For comparison, the table also provides personality type figures for the Naval Academy overall, and estimates for the U.S. population according to Hammer and Mitchell (1996). ${ }^{2}$

\section{(Table 1 about here)}

The percentages for our experiment are the end-product of the recruitment process and the choice of subjects to volunteer. As evident from the table, they do not reflect perfectly the actual percentages of types either at the Naval Academy or in the general population. Furthermore, the personality preference categories are largely independent for our subject pool. That is, there is little systematic correlation across the preference categories. We follow the dichotomous approach recommended by the developers of the MBTI for statistical purposes. That is, we use

\footnotetext{
${ }^{2}$ See Myers, et al (1998) for more information on the distribution of types for males, females, and various ethnic groups.
} 
binary classifications of individuals for the four pairwise personality dichotomies rather than raw scores.

Based on descriptions of types provided by the MBTI, we test the following formal hypotheses ${ }^{3}$ :

H1: Individuals with a preference for extraversion (E) in orientation and/or feeling $(F)$ in judgment will exhibit more cooperative or other-regarding behavior than those with preferences for introversion (I) and/or thinking (T). This implies the following behavioral hypotheses for $\mathrm{E}$ and/or $\mathrm{F}$ type individuals in our games:

H1a. Dictator game - make higher offers H1b. Ultimatum game - make higher offers, be less likely to reject H1c. Trust game - make higher offers, return greater \% H1d. Prisoner's dilemma - choose the cooperative strategy more often

Our hypotheses are based on our interpretation of how more socially oriented, more cooperative, and more other-regarding behavior should manifest itself in each of the four experiments. We examine these hypotheses using one-tailed tests because each of the hypotheses implies more cooperative behavior from $\mathrm{E}$ and $\mathrm{F}$ types.

We also hypothesize that extraversion (E) when combined with feeling (F) should result in an even stronger desire to avoid interpersonal disharmony. This is based on Myers, et al's (1998) description of persons with the combination of extraversion (E) and feeling (F) as "action-oriented cooperators" who "like to make things happen for the pleasure and welfare of others. They focus on liking others and being liked and on connecting people with each other" (p. 58).

\footnotetext{
${ }^{3}$ Note that our personality hypotheses concern only main effects and two-way interactions. While more complex interactions may exist among the personality dichotomies and gender, we have little theoretical basis for establishing predictions regarding such deeper interactions. Therefore, we neither hypothesize about nor test for these more complex dynamics.
} 
Finally, because the mental function of perception (sensing versus intuition) describes only how individuals tend to acquire information, we have no basis for translating differences in perception into differences in observed behavior in the context of the four games. We believe the acquisition of information is not the fundamental mental function of interest in these games, as the games are fairly simple and transparent. The more interesting dynamic stems from the individual's need to balance monetary gain with their own internal values and beliefs, and this is predominantly a function of judgment and not of perception. Similarly, we have no basis for translating differences in the attitude dimension (judging versus perception) into behavioral hypotheses.

Our research is connected to previous experiments that investigated the role of psychological characteristics, including personality preferences, in explaining individual decisions in laboratory economics experiments. Two studies are particularly relevant. Boone, et al (1999) examine the correlation between the choice of cooperative or non-cooperative play in a prisoner’s dilemma game and four personality attributes: (i) locus of control, (ii) self-monitoring, (iii) type-A behavior, and (iv) sensation seeking. They find that internal locus of control, high self-monitoring, and high sensation are all positively correlated with cooperative behavior, particularly in repeated games, while type-A behavior decreases the likelihood of cooperation.

Brandstätter and Güth (2002) examine the role of personality in bargaining games through a series of experiments in which subjects participated successively in a dictator game, an ultimatum game, and a combination game. They find that subjects' self-reported "benevolence" is more important for offers when the responder is "powerless" (as in the dictator game) than when he is "powerful” (as in the ultimatum game). They also find that powerful responders' scores on "social reciprocity" are positively correlated with how much they expect to receive 
from proposers. They find no significant correlation between self-reported levels of “intelligence” and either offers or demands.

The personality characteristics of the subjects in Boone, et al (1999) and Brandstätter and Güth (2002) were both elicited in close connection with administration of their experiments. Our subjects' personality preferences were elicited in a different setting, up to four years prior to the experiment. It is important to test whether personality effects are genuine or due to framing associated with the personality test instrument.

Our experiments also differ significantly from the other studies in design and setting. In both previous studies, subjects were located in the same room. In Boone, et al (1999), subjects participated face-to-face in a single, large room, and subject names and earnings were announced to the group at the conclusion of the experiment. Only the three top earners in the experiment were rewarded. In Brandstätter and Güth (2002) subjects played repeatedly in the same role as proposer or responder, although participants were randomly re-matched. As such, their results may be influenced by learning or sequencing effects. We avoid these effects by using simple, anonymous, one-shot games.

Previous studies have also examined the relationship between gender and behavior in laboratory economics experiments, with mixed results. Whereas Bolton and Katok (1995) find no differences between women and men in their dictator game experiments, Eckel and Grossman (1998) find that women donate about twice as much as men in their double-anonymous dictator game. Solnick (1997) finds little difference in mean offers between men and women in an ultimatum game, but higher rates of rejections by females, while Eckel and Grossman (2001) find higher offers by females and more frequent rejections by males. Brown-Kruse and Hummels 
(1993) find that all-male groups contribute more than all-female groups in a public-goods game, while Nowell and Tinkler (1994) find that all-female groups contribute more.

The mixed results described above may be explained in part by the fact that each of these studies may be ignoring important correlations between gender and psychological characteristics. For example feeling judgment, is more common in females (75.5\%) than in males (43.5\%) (Myers, et al, 1998, p. 157-8). It may be the case, therefore, that a cohort of thinking females behaves no differently than a cohort of thinking males, or that a cohort of feeling females behaves no differently than a cohort of feeling males, and that gender alone is relatively unimportant. Boone, et al (1999) find some evidence (p. 367) of gender effects being confounded with effects attributable to the personality attributes of type-A versus type-B persons. Controlling for differences in judgment and orientation preferences in our subject pool, therefore, provides a testable hypothesis that gender alone will have no impact on subjects’ decisions:

\section{H2: Controlling for personality characteristics, no difference in decisions is expected between males and females.}

Because this hypothesis may be rejected if males are either more or less cooperative than females, we use two-tailed tests. We now present our experimental results in the following subsections followed by discussion in Section 5 .

\section{Results}

Table 2 provides summary statistics for each of the four experiments.

\section{(Table 2 about here)}

As expected, we found subject decisions to be markedly different, on average, from the standard game-theoretic predictions. The overall results are qualitatively consistent with many experimental studies and are not the outcome of most interest in the current analysis. Several 
comparative items, however, are noteworthy. Average offers in the dictator game (\$7.09) and ultimatum game (\$6.60) are somewhat higher than in previous studies, and the higher average offer in the dictator game is not consistent with previous research that typically finds higher average offers in the ultimatum game. ${ }^{4}$ Furthermore, subjects exhibited stronger than expected feelings of trust with the amount sent in the trust game averaging $\$ 8.85$ and $70 \%$ of subjects sending \$10, their entire endowment. In addition, in the prisoner dilemma games $54 \%$ of subjects chose to cooperate. These results may be reflective of a subject pool (students at a military academy) for which there is relatively little social distance.

The main thrust of this paper, however, is to investigate whether differences in personality variables and gender lead to measurable differences in subjects’ decisions. Furthermore, we are interested in whether the patterns of behavior are consistent with those implied by theories of psychological type.

We use regression analysis to control for individual subject characteristics and test our behavioral hypotheses. Our regressions for the dictator, ultimatum, and trust games use the dollar amount offered as the dependent variable, with independent variables including dummies for the four personality dichotomies ( $\mathrm{E}$ - prefers Extraversion in orientation, $\mathrm{N}$ - prefers using Intuition in perception, $\mathrm{T}$ - prefers Thinking judgment, and $\mathrm{J}$ - prefers Judgment in attitude towards outside world), Gender (1 if Male), and class status ${ }^{5}$ (1 if Senior, 0 otherwise). We also include regressions for the percentage returned in the trust game ${ }^{6}$ and a binary logistic regression for

\footnotetext{
${ }^{4}$ These differences may also be attributed to the lack of a show-up fee (implying Player 2 might be penniless at the end of the experiment). Although offers in our dictator game were higher than in the ultimatum game, the difference is not statistically significant.

${ }^{5}$ Students at USNA follow a strict four-year academic program. Seniors are students in their final year of study. The Senior dummy was the only class dummy variable retained in the final regressions based on significance.

${ }^{6}$ The dependent variable is limited from 0 to 1 (one person returned $0 \%$ and one person returned $100 \%$ ). A Tobit regression yields results that are qualitatively virtually identical to those reported here using OLS.
} 
choices in the prisoner's dilemma game (with defect $=1$ ). Because only 4 out of 47 offers were rejected in our ultimatum game (all by male thinking types, two of whom were extraverted), the number of rejections is inadequate for any meaningful comparisons to be made between personality types or genders. Table 3 presents the main-effects regression results. A second set of regressions drop the main-effects personality dummies and use only a two-way EF interaction dummy to capture the preference combination of extraversion with feeling. Table 4 presents the interaction-effect regression results. Because each of the independent variables is dichotomous, the coefficients are interpreted as differences in conditional means.

With appropriate controls for personality preferences, we find no evidence of behavioral differences based on gender, as is evident in Table 3.

\section{(Table 3 about here)}

The regression coefficients indicate that males offered more in the dictator and trust games, but offered less in the ultimatum game, returned a smaller percentage in the trust game and chose to defect more often in the prisoner's dilemma game. Importantly, none of the regression coefficients on gender is statistically significant. ${ }^{7}$ In general, our results support hypothesis H2. Surprisingly, the regression results indicate that seniors were less cooperative in most environments. Offers for seniors were lower in the dictator, ultimatum, and trust games, as was the percentage returned in the trust game.

The results with respect to the impact of the main effects personality variables are mixed. In particular, we find that E types exhibited more cooperative behavior in the ultimatum, trust,

\footnotetext{
${ }^{7}$ Thus, although males offered more in the dictator game (averages of $\$ 7.30$ for males and $\$ 6.45$ for females) and trust game (\$9.09 vs. \$8.03), males offered exactly the same in the ultimatum game (\$6.60), returned a smaller percentage in the trust game ( 0.38 vs. 0.44$)$, and chose to defect more often in the prisoner's dilemma ( 0.47 vs. 0.44 ), none of these differences is statistically significant.
} 
and prisoner's dilemma games, but offered less in the dictator game and returned a smaller percentage in the trust game. While the differences in offers for the ultimatum and trust games are statistically significant at the $10 \%$ level, the other coefficients for the E types are not. The regression results also indicate that feeling types offered more in the dictator and trust games, returned a greater percentage in the trust game, and chose to defect less often in the prisoner's dilemma. However, $\mathrm{F}$ types offered less in the ultimatum game, and none of the regression coefficients approach standard significance levels. Thus, in most cases the point estimates from our regression models support the hypothesis that $\mathrm{E}$ and $\mathrm{F}$ types exhibit more cooperative behavior. The significance results, however, provide only limited support for this hypothesis. The results (in particular the lack of significant coefficients on the $\mathrm{E}$ and $\mathrm{F}$ variables) led us to consider a second econometric specification in which we drop the main effects personality variables and include an interaction term for EF types. Table 4 presents these regression results.

\section{(Table 4 about here)}

The combination of a preference for extraversion in orientation and feeling in judgment generates results that are supportive of H1. The point estimates show that EF types offered more in the dictator, ultimatum and trust games, returned a greater percentage in the trust game, and chose the cooperative strategy more often in the prisoner's dilemma game. The coefficients on EF are statistically significant for ultimatum offers, the amount returned in the trust game and the strategy chosen in the prisoner's dilemma game. Some basic descriptive statistics further illustrate this point. In the dictator game, EF types offered $\$ 7.83$ vs. $\$ 6.96$ for non-EF’s, in the ultimatum game EF types offered $\$ 8.42$ vs. $\$ 6.34$ for non-EF's, and in the trust game EF types offered $\$ 9.00$ vs. $\$ 8.78$ for non-EF’s. Furthermore, the percentage returned in the trust game was 0.49 for EF's vs. 0.39 for non-EF's, and the percentage choosing to defect in the prisoner's 
dilemma was 0.31 for EF's and 0.51 for non-EF's. In addition to supporting H1, the results support H2 in that we find no evidence for behavioral differences on the basis of gender. Consistent with the results from Table 3, seniors offered less in the dictator, ultimatum, and trust games, and returned a greater percentage in the trust game, and the coefficient estimate is statistically significant for the dictator game. Also, the p-values on the senior dummy approach standard levels of significance for offers in the ultimatum game (two sided p-value $=0.13$ ) and the percentage returned in the trust game (two sided p-value 0.16).

\section{Discussion and Conclusions}

To summarize our findings, we conclude that behavior in non-cooperative laboratory economics experiments is influenced by personality variables and is weakly consistent with predictions based on psychological type. It is important to note that we find evidence of the importance of personality despite the fact that our subject pool (U.S. Naval Academy students) is largely homogeneous (non-minority males between the ages of 18-25) and all students complete a common rigorous military and academic training program (thereby potentially instilling a set of common values and decreasing social distance). Individuals characterized as having a preference both for extraversion in orientation and feeling in judgment generally exhibited more cooperative or other-regarding behavior than other types, but it seems that these two characteristics must be together for the effect to be significant. Furthermore, and in contradiction to Brandstätter and Güth (2002), we found that personality was more important when the responder was “powerful” as in the ultimatum game, than when he was "powerless" as in the dictator game.

We also found little systematic difference between males and females. Importantly, with appropriate controls for personality preferences, none of the regression coefficients on gender was statistically significant in any of the specifications we utilize. Lastly, a result that we had not 
anticipated a priori was that seniors at USNA noticeably exhibited the least cooperative or otherregarding behavior in four out of five cases (dictator game offers, ultimatum game offers, trust game offers, and trust game responses). On this basis, we conclude that seniority breeds feelings of entitlement.

However, although we find statistically significant differences for some personality types, the results from our main effects regressions provide only limited support for the importance of the four personality type indicators on their own. This could be due to several factors that could only be isolated through additional research. If the differences in behavior due to personality type are fairly small, a larger sample size may be required to generate statistically significant coefficients. Second, subjects may be influenced by many factors including income, religious beliefs, experimental treatment effects, mood, etc, none of which are captured by gender or the personality test instrument. Third, personality attributes may be relatively important, but the test instrument used may be insufficient or may not identify the most relevant factors. Nevertheless, this research highlights the importance of considering preferences about how subjects acquire information, make decisions, and interact with others in laboratory experiments. 


\section{References}

Ben-Ner, Avner, Fanmin Kong, and Louis Putterman. (2004). "Share and Share Alike? GenderPairing, Personality, and Cognitive Ability as Determinants of Giving,” Journal of Economic Psychology 25(5), 581-89.

Berg, J., J. Dickhaut, and K. McCabe. (1995). “Trust, Reciprocity, and Social History,” Games and Economic Behavior 10, 122-142.

Bolton, G. and E. Katok. (1995). “An Experimental Test for Gender Differences in Beneficent Behavior,” Economics Letters 48, 287-92.

Boone, Christopher, Bert De Branbander, and Arjen van Witteloostuijn. (1999). “The Impact of Personality on Behavior in five Prisoner's Dilemma Games,” Journal of Economic Psychology 20, 343-377.

Brandstätter, Hermann, and Werner Güth. (2002). "Personality in Dictator and Ultimatum Games,” Central European Journal of Operations Research 10, 191-215.

Brown-Kruse, J. and D. Hummels. (1993). “Gender Effects in Laboratory Public Goods Contribution,” Journal of Economic Behavior and Organization 22, 255-267.

Burks, Stephen, Jeffrey Carpenter, and Eric Verhoogen. (2003). "Playing Both Roles in the Trust Game,” Journal of Economic Behavior and Organization 51(2), 195-216.

Costa, P.T. Jr. and R. R. McCrae. (1985). The NEO Personality Inventory Manual. Odessa, FL. Psychological Assessment Resources.

Eckel, Catherine C., and P. J. Grossman. (2001). “Chivalry and Solidarity in Ultimatum Games,” Economic Inquiry 39 (2), $171-188$.

Eckel, Catherine C., and P. J. Grossman. (1998). “Are Women Less Selfish than Men?: Evidence from Dictator Experiments,” Economic Journal 108 (May), 726-735. 
Güth, W., R. Schmittberger, and B. Schwarze. (1982). “An Experimental Analysis of Ultimatum Bargaining,” Journal of Economic Behavior and Organization 3, 367-388.

Hammer, A.L. and Wayne D. Mitchell. (1996). "The Distribution of MBTI types in the U.S. by Gender and Ethnic Group,” Journal of Psychological Type 37, 2-15.

Jenkins, C.D., S.J. Zyzanski, and R.H. Rosenman. (1979) Jenkins Activity Survey Manual N.Y.: Psychological Corp.

Jung, C. G. (1923). Psychological types. Princeton, NJ: Princeton University Press.

Kagel, J. and K. W. Wolfe. (2001). “Tests of Fairness Based on Equity Considerations in a Three-Person Ultimatum Game,” Experimental Economics 4, 203 - 219.

Kahneman, Daniel, and Jack Knetsch, and Richard H. Thaler. (1986). "Fairness and the Assumptions of Economics,” Journal of Business 76, 798-41.

Ma, Leanne, et al. (2002). “Altruism and Voluntary Provision of Public Goods,” Economics Bulletin 3(31), 1-8.

McCrae, R. and P. Costa. (1989). "Reinterpreting the Myers-Briggs Type Indicator from the Perspective of the Five-Factor Model,” Journal of Personality 57, 17-40.

Myers, Isabel Briggs, Mary H. McCaulley, Naomi L. Quenk, and Allen L. Hammer. (1998). MBTI Manual: A Guide to the Development and Use of the Myers Briggs Type Indicator. Palo Alto, CA: Consulting Psychologists Press.

Nowell, C. and S. Tinkler. (1994). "The Influence of Gender on the Provision of a Public Good," Journal of Economic Behavior and Organization 25, 25-36.

Quenk, Naomi L. (2000). Essentials of Myers-Briggs Type Indicator Assessment. New York, NY: John Wiley Sons, Inc. 
Schmitt, P., R. Shupp, K. Swope, and J. Mayer. (2004). "Personality Preferences and PreCommitment: Behavioral Explanations in Ultimatum Games,” unpublished manuscript.

Solnick, Sara J. (2001). “Gender Differences in the Ultimatum Game,” Economic Inquiry 39 (2) $189-200$.

Thorne, A. and H. Gough. (1991). Portraits of Type: An MBTI Research Compendium. Palo Alto, CA: Consulting Psychologists Press, Inc. 


\section{Tables}

Table 1. Subject summary by MBTI dichotomy and gender

\begin{tabular}{|c|c||c|c||c|c|}
\multicolumn{2}{c}{ Experiment } & \multicolumn{2}{c|}{ U.S. Naval Academy*** } & \multicolumn{2}{c|}{ U.S. Population** } \\
\hline & & & & & \\
\hline \hline $\mathrm{E}$ & $\mathrm{I}$ & $\mathrm{E}$ & $\mathrm{I}$ & $\mathrm{E}$ & $\mathrm{I}$ \\
$53 \%$ & $47 \%$ & $56 \%$ & $43 \%$ & $46.3 \% \%$ & $53.7 \%$ \\
\hline $\mathrm{N}$ & $\mathrm{S}$ & $\mathrm{N}$ & $\mathrm{S}$ & $\mathrm{N}$ & $\mathrm{S}$ \\
$53 \%$ & $47 \%$ & $42 \%$ & $57 \%$ & $31.9 \%$ & $68.1 \%$ \\
\hline $\mathrm{T}$ & $\mathrm{F}$ & $\mathrm{T}$ & $\mathrm{F}$ & $\mathrm{T}$ & $\mathrm{F}$ \\
$67 \%$ & $33 \%$ & $75 \%$ & $24 \%$ & $52.9 \%$ & $47.1 \%$ \\
\hline $\mathrm{J}$ & $\mathrm{P}$ & $\mathrm{J}$ & $\mathrm{P}$ & $\mathrm{J}$ & $\mathrm{P}$ \\
$53 \%$ & $47 \%$ & $59 \%$ & $40 \%$ & $58.1 \%$ & $41.9 \%$ \\
\hline \hline Male & Female & Male & Female & Male* & Female* \\
$78 \%$ & $22 \%$ & $85 \%$ & $15 \%$ & $49.1 \%$ & $50.9 \%$ \\
\hline
\end{tabular}

*Source: U.S. Census Bureau, Census 2000

**Source: Hammer and Mitchell (1996)

***Approximately $1 \%$ of students have no recorded MBTI results. 
Table 2. Summary statistics

\begin{tabular}{|c|c|c|c|c|}
\hline Experiment & Details & Obs. & Mean & $\begin{array}{c}\text { Std. } \\
\text { Deviation }\end{array}$ \\
\hline Dictator & \$15 Pie & $\mathrm{N}=40$ & $\$ 7.09$ & $\$ 4.56$ \\
\hline Ultimatum & $\$ 15$ Pie & $\mathrm{N}=47$ & $\$ 6.60$ & $\$ 1.95$ \\
\hline $\begin{array}{c}\text { Trust } \\
\text { (Sent) }\end{array}$ & $\begin{array}{c}\$ 10 \\
\text { to start }\end{array}$ & $\mathrm{N}=47$ & $\$ 8.85$ & $\$ 2.23$ \\
\hline $\begin{array}{c}\text { Trust (Returned) } \\
\% \text { Returned }\end{array}$ & $\mathrm{N}=47$ & $41 \%$ & $18 \%$ \\
\hline $\begin{array}{c}\text { Prisoner's } \\
\text { Dilemma }\end{array}$ & $\begin{array}{c}\% \\
\text { Defect }\end{array}$ & $\mathrm{N}=48$ & $46 \%$ & \\
\hline
\end{tabular}


Table 3. Regression results for main effects (standard errors in parentheses)

\begin{tabular}{|c|c|c|c|c|c|}
\hline $\begin{array}{c}\text { Independent } \\
\text { Variable }\end{array}$ & $\begin{array}{c}\text { Dictator } \\
\text { Game } \\
\text { Offers }\end{array}$ & $\begin{array}{l}\text { Ult. } \\
\text { Game } \\
\text { Offers }\end{array}$ & $\begin{array}{l}\text { Trust } \\
\text { Game } \\
\text { Offers }\end{array}$ & $\begin{array}{c}\text { Trust } \\
\text { Game: } \\
\text { Percent } \\
\text { Returned }\end{array}$ & $\begin{array}{c}P D \\
1=D e f e c t\end{array}$ \\
\hline Constant & $\begin{array}{l}6.89^{++} \\
(2.33)\end{array}$ & $\begin{array}{l}6.62^{++} \\
(0.75)\end{array}$ & $\begin{array}{l}7.57^{++} \\
(1.05)\end{array}$ & $\begin{array}{l}0.08 \\
(0.18)\end{array}$ & $\begin{array}{l}-.076 \\
(0.76)\end{array}$ \\
\hline $\begin{array}{l}\text { Amount } \\
\text { Given }\end{array}$ & - & - & - & $\begin{array}{l}0.04^{++} \\
(0.02)\end{array}$ & - \\
\hline E & $\begin{array}{r}-0.86 \\
(1.51)\end{array}$ & $\begin{array}{c}0.78^{*} \\
(0.57)\end{array}$ & $\begin{array}{c}1.14^{*} \\
(0.70)\end{array}$ & $\begin{array}{l}-0.01 \\
(0.05)\end{array}$ & $\begin{array}{l}-0.04 \\
(0.63)\end{array}$ \\
\hline $\mathrm{N}$ & $\begin{array}{r}-0.49 \\
(1.57)\end{array}$ & $\begin{array}{l}-0.86^{*} \\
(0.57)\end{array}$ & $\begin{array}{c}-0.49 \\
(0.68)\end{array}$ & $\begin{array}{c}0.03 \\
(0.05)\end{array}$ & $\begin{array}{c}0.73 \\
(0.66)\end{array}$ \\
\hline $\mathrm{F}$ & $\begin{array}{c}1.15 \\
(1.76)\end{array}$ & $\begin{array}{c}0.72 \\
(0.66)\end{array}$ & $\begin{array}{c}-0.51 \\
(0.70)\end{array}$ & $\begin{array}{c}0.07 \\
(0.06)\end{array}$ & $\begin{array}{l}-0.14 \\
(0.70)\end{array}$ \\
\hline $\mathrm{J}$ & $\begin{array}{c}1.03 \\
(1.52)\end{array}$ & $\begin{array}{c}0.74 \\
(0.59)\end{array}$ & $\begin{array}{l}0.73 \\
(0.74)\end{array}$ & $\begin{array}{l}0.01 \\
(0.06)\end{array}$ & $\begin{array}{c}0.40 \\
(0.66)\end{array}$ \\
\hline $\mathrm{EF}$ & - & - & - & - & - \\
\hline MALE & $\begin{array}{l}1.07 \\
(1.76)\end{array}$ & $\begin{array}{r}-0.35 \\
(0.96)\end{array}$ & $\begin{array}{c}1.13 \\
(0.76)\end{array}$ & $\begin{array}{l}-0.07 \\
(0.07)\end{array}$ & $\begin{array}{c}0.08 \\
(0.67)\end{array}$ \\
\hline SR & $\begin{array}{l}-3.17+ \\
(1.81)\end{array}$ & $\begin{array}{c}-0.97 \\
(0.72)\end{array}$ & $\begin{array}{l}-0.33 \\
(0.85)\end{array}$ & $\begin{array}{l}-0.06 \\
(0.07)\end{array}$ & $\begin{array}{l}-0.38 \\
(0.80)\end{array}$ \\
\hline $\mathrm{R}^{2}$ & 0.116 & 0.167 & 0.12 & 0.188 & - \\
\hline Adj. $\mathrm{R}^{2}$ & -0.044 & 0.042 & -0.012 & 0.039 & - \\
\hline $\begin{array}{l}\text { Sig. F } \\
\text { Nagelkerke } \\
\mathrm{R}^{2}\end{array}$ & $\begin{array}{r}0.634 \\
-\quad\end{array}$ & $\begin{array}{r}\quad 0.263 \\
-\quad\end{array}$ & $\begin{array}{r}0.496 \\
-\quad\end{array}$ & 0.177 & 0.023 \\
\hline $\begin{array}{l}\text { Sig. Chi- } \\
\text { Square }\end{array}$ & - & - & - & - & 0.956 \\
\hline $\mathrm{N}$ & 40 & 47 & 47 & 46 & 48 \\
\hline
\end{tabular}


Table 4. Regression results with an interaction term for EF types (standard errors in parentheses)

\begin{tabular}{|c|c|c|c|c|c|}
\hline $\begin{array}{c}\text { Independent } \\
\text { Variable }\end{array}$ & $\begin{array}{c}\text { Dictator } \\
\text { Game } \\
\text { Offers }\end{array}$ & $\begin{array}{l}\text { Ult. } \\
\text { Game } \\
\text { Offers }\end{array}$ & $\begin{array}{l}\text { Trust } \\
\text { Game } \\
\text { Offers }\end{array}$ & $\begin{array}{c}\text { Trust } \\
\text { Game: } \\
\text { Percent } \\
\text { Returned }\end{array}$ & $\begin{array}{c}P D \\
1=D e f e c t\end{array}$ \\
\hline Constant & $\begin{array}{l}6.91^{++} \\
(1.48)\end{array}$ & $\begin{array}{l}6.52^{++} \\
(0.32)\end{array}$ & $\begin{array}{l}8.32^{++} \\
(0.65)\end{array}$ & $\begin{array}{l}0.13 \\
(0.14)\end{array}$ & $\begin{array}{c}-0.19 \\
(0.52)\end{array}$ \\
\hline $\begin{array}{l}\text { Amount } \\
\text { Given }\end{array}$ & - & - & - & $\begin{array}{l}0.04^{++} \\
(0.01)\end{array}$ & - \\
\hline E & - & - & - & - & - \\
\hline $\mathrm{N}$ & - & - & - & - & - \\
\hline F & - & - & - & - & - \\
\hline $\mathrm{J}$ & - & - & - & - & - \\
\hline $\mathrm{EF}$ & $\begin{array}{l}1.06 \\
(2.02)\end{array}$ & $\begin{array}{l}2.39 * * \\
(0.82)\end{array}$ & $\begin{array}{c}0.28 \\
(0.71)\end{array}$ & $\begin{array}{l}0.14^{* *} \\
(0.07)\end{array}$ & $\begin{array}{l}-1.03^{*} \\
(0.73)\end{array}$ \\
\hline MALE & $\begin{array}{l}0.97 \\
(1.67)\end{array}$ & $\begin{array}{c}0.01 \\
(0.88)\end{array}$ & $\begin{array}{c}0.76 \\
(0.71)\end{array}$ & $\begin{array}{l}-0.08 \\
(0.07)\end{array}$ & $\begin{array}{l}0.44 \\
(0.66)\end{array}$ \\
\hline SR & $\begin{array}{l}-2.85^{*} \\
(1.67)\end{array}$ & $\begin{array}{l}-1.00 \\
(0.65)\end{array}$ & $\begin{array}{l}-0.40 \\
(0.85)\end{array}$ & $\begin{array}{l}-0.09 \\
(0.06)\end{array}$ & $\begin{array}{l}-0.003 \\
(0.77)\end{array}$ \\
\hline $\mathrm{R}^{2}$ & 0.085 & 0.176 & 0.033 & 0.227 & - \\
\hline Adj. $R^{2}$ & 0.009 & 0.118 & -0.034 & 0.151 & - \\
\hline Sig. F & 0.354 & 0.04 & 0.689 & 0.029 & - \\
\hline $\begin{array}{l}\text { Nagelkerke } \\
\mathrm{R}^{2}\end{array}$ & - & - & - & - & 0.032 \\
\hline $\begin{array}{l}\text { Sig. Chi- } \\
\text { Square }\end{array}$ & - & - & - & - & 0.548 \\
\hline $\mathrm{N}$ & 40 & 47 & 47 & 46 & 48 \\
\hline \multicolumn{3}{|c|}{$\begin{array}{l}\text { Significant at } 10 \% \text { level, one tailed test } \\
* \text { ** } \\
\text { significant at } 5 \% \text { level, one tailed test }\end{array}$} & \multicolumn{3}{|c|}{ 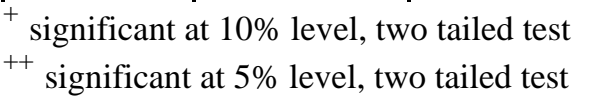 } \\
\hline
\end{tabular}


Figures

Figure 1. Jungian theory of psychological type
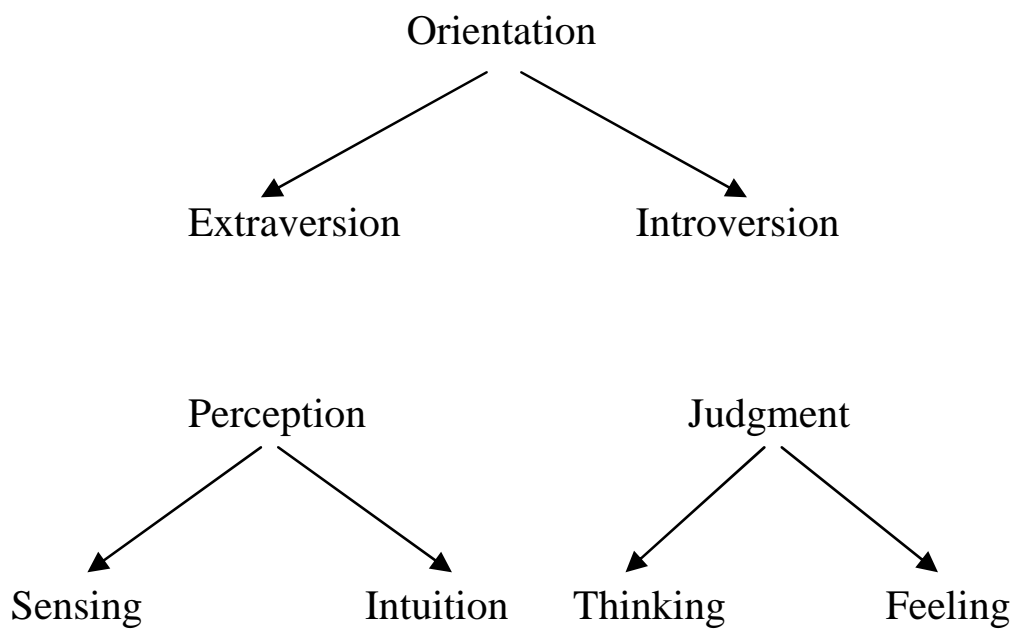
Figure 2. Subject summary by whole type

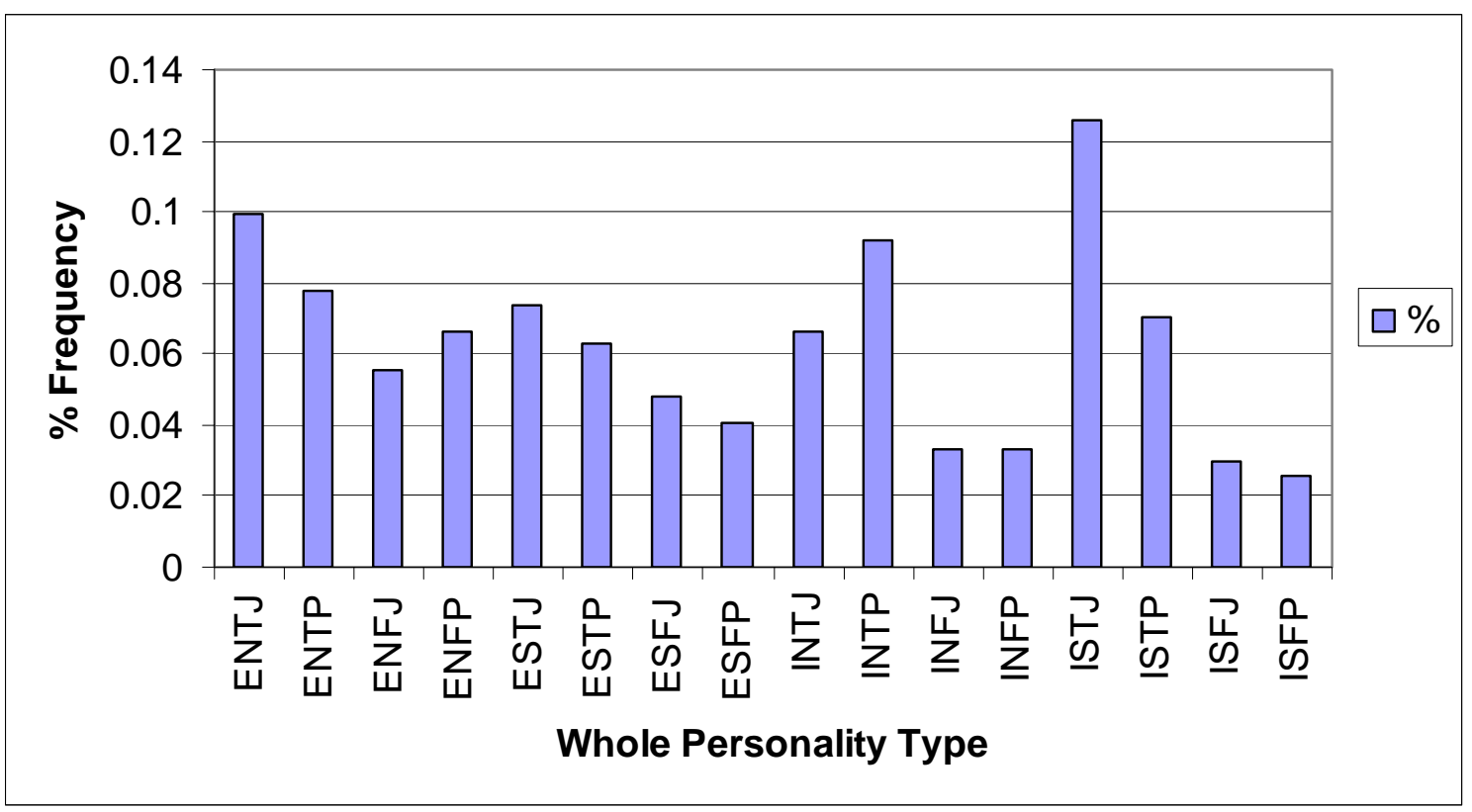

